\title{
Lecciones del pasado. ¿podemos aprender algo de las epidemias anteriores?
}

\author{
Teachings from the past. Can we learn from previous epidemics?
}

\author{
Juan-Carlos Eslava-Castañeda ${ }^{1}$
}

Forma de citar: Eslava JC. Lecciones del pasado. ¿podemos aprender algo de las epidemias anteriores?. Salud UIS. 2020; 52(4): 468-476. doi: https://doi.org/10.18273/revsal.v52n4-2020015 @c) (1)

Desde el comienzo de la actual pandemia de COVID 19, atribuida a un nuevo agente viral identificado como SARS-CoV-2, la referencia a otras epidemias no se hizo esperar. Ya fuese para resaltar lo novedoso de la actual o, por el contrario, para mostrar las continuidades o reiteraciones en la historia, los sucesos del pasado han estado muy presentes en las reflexiones del ahora. Y no es para menos, dado que la incertidumbre y angustia del presente nos ha puesto en una situación especial, proclive a buscar enseñanzas tanto en los logros como en las equivocaciones del pasado.

Lo más común ha sido evocar lo ocurrido en la epidemia de gripe de 1918, dado que su condición de pandemia, causada por un agente viral y con una significativa mortalidad, se torna una condición análoga a la que estamos viviendo. Pero, por supuesto, la referencia a otras grandes epidemias también ha sido recurrente: desde las más cercanas en el tiempo, como el Ébola, MERS, SARS y Zika hasta las más distantes, como la peste de Justiniano y la peste de Atenas, pasando por la gripe H1N1, el SIDA, la poliomielitis, la viruela, y la peste negra.

Todas estas epidemias han servido de contraste para intentar entender la situación actual y para calmar los ánimos de una aturdida humanidad, al hacer conciencia no sólo de que las epidemias han sido una constante en nuestra historia sino que, a pesar de ellas, hemos logrado sobrevivir y avanzar en el terreno tortuoso de la existencia. Pero, claro está, no sólo se ha recurrido a la historia buscando mayor sosiego, también se ha recurrido a ella buscando lecciones de más concreta utilidad.

Ante ello, cabe preguntarse: ¿podemos aprender algo de las epidemias pasadas? Y nuestra explícita respuesta afirmativa nos permitirá buscar algunas lecciones en la historia. Pero cabe señalar que, hasta hace poco, ésta no era una opinión compartida por todos, dado que entre muchas personas existía la presuntuosa actitud de mirar hacia atrás desde lo logros del presente, y sólo reconocer en el pasado desacierto y falsedad. Sin embargo, la actual pandemia ha aplacado esa maliciosa arrogancia, al enfrentarnos a una situación límite que no encuentra una clara y contundente respuesta, aun con todos nuestros imponentes recursos científico-técnicos.

Claro que esa emergente humildad puede deberse a las ansiedades del presente, pues como ha dicho el reconocido historiador de la medicina y experto en el análisis de las enfermedades del pasado, Charles Rosenberg, las epidemias suelen tener un ciclo que inicia con la negación, pasa por la resignación y llega al olvido, tal como nos lo recuerda el también reconocido historiador de la medicina Marcos Cueto ${ }^{1}$ y lo reitera nuestro colega más cercano Abel Martínez².

1. Universidad Nacional de Colombia. Bogotá, Colombia.

Correspondencia: Juan Carlos Eslava. Dirección: Carrera 45 26-85. Teléfono: +1 3165000 Ext 15073. Correo electrónico: jceslavac@unal.edu.co 
En todo caso, es de resaltar que la historia ha recobrado cierta importancia y, tal como lo ha señalado el profesor de la Escuela de Medicina de Harvard David S. Jones, en medio de esta crisis, la labor de los historiadores tiene mucho que ofrecer ${ }^{3}$. Esto es así porque, a diferencia de muchos de los médicos, salubristas y científicos actuales que habían dejado de lado la preocupación por las enfermedades infecciosas y las grandes epidemias, asumiendo que eran azotes pretéritos sin mayor misterio o atractivo para el presente, muchos historiadores médicos han dedicado parte de sus vidas a entender la complejidad que conlleva la experiencia epidémica en la historia.

Y esa comprensión histórica ha permitido, entre otras cosas, apreciar el estrecho vínculo entre los fenómenos biológicos y los fenómenos sociales, haciendo no sólo más clara la importancia de las causas socioambientales de las epidemias ${ }^{4}$, sino resaltando las profundas consecuencias sociales que ellas tienen ${ }^{5,6}$. Por supuesto, la perspectiva histórica no es exclusiva de los historiadores profesionales puesto que investigadores de diferentes áreas, incluyendo la virología, la epidemiología y la salud pública, son refinados cultores de dicha perspectiva. Baste recordar la obra de Michael Oldstone ${ }^{7}$, Jaime Breilh ${ }^{8}$ y Saúl Franco ${ }^{9}$, entre muchos otros.

Pero volviendo a la pregunta de base, referida a los aprendizajes que se pueden lograr del estudio de las experiencias epidémicas pasadas, cabe señalar dos maneras diversas pero complementarias de abordar el asunto. Por un lado, se puede leer el pasado como fuente de inspiración para entender el presente, resaltando grandes generalidades que ayuden a tener una comprensión más amplia y profunda de todo fenómeno epidémico. Pero, por otro lado, se puede hacer un análisis más minucioso de los hechos epidémicos y las medidas implementadas, a la luz de los conocimientos más actuales, para refinar formas de aproximación más potentes y propuestas de acción más adecuadas de cara a la actual pandemia y a las epidemias que, con seguridad, estarán por venir.

En el presente texto, se asumirá esta doble manera de estudiar el asunto recurriendo al análisis de lo ocurrido en algunas epidemias del pasado. Además, se combinará una perspectiva global con ejemplos locales, para aprovechar la experiencia mundial sin dejar de lado nuestra propia historia. Por supuesto, la epidemia de gripe de 1918 tendrá un gran protagonismo, toda vez que ella ha sido estudiada con mucho detalle a nivel internacional y también cuenta, hoy en día, con un saber acumulado importante a nivel nacional. Sin embargo, este no será el único caso que se mencione puesto que los estudios de otras epidemias permiten establecer, en conjunto, unas lecciones más globales.

\section{Lecciones generales del estudio de las epidemias}

Aun cuando haya quien afirma que lo único que enseña la historia de las pandemias es que no se nos puede enseñar ${ }^{10}$, el acuerdo mayoritario de quienes estudian la historia de las epidemias es que sí se pueden sacar varias lecciones del pasado. Estas tienen un alcance general y resultan de gran interés si se logra vencer esa tendencia a su olvido. Por lo pronto, resultan de interés cinco de estas enseñanzas, las cuales se discutirán a continuación.

En primer lugar, cabe señalar que las epidemias ejercen una fuerte presión sobre las sociedades y afectan de manera intensa la vida de las personas. Y esto no se debe menospreciar. Como ha sido documentado ampliamente, el desconcierto y el desorden social se presentan de modo frecuente en toda epidemia, pero su alcance depende de la envergadura de la misma, los recursos que se tengan a la mano para enfrentarla y el contexto sociopolítico en el cual aparece. Por supuesto, el impacto del fenómeno epidémico está íntimamente ligado a los procesos históricos que se están desarrollando en el momento de su emergencia.

Empecemos por esto último. Se ha afirmado, por ejemplo, que la peste de Atenas contribuyó significativamente a la caída del poderío ateniense y a su derrota frente a Esparta ${ }^{11}$ y que la plaga de Justiniano, que afectó el Imperio bizantino en el siglo VI d.C., fue uno de los acontecimientos fundamentales que propició el derrumbe del mundo antiguo y la irrupción de la llamada Edad Media ${ }^{12}$, mientras que la muy conocida epidemia de peste negra ha sido considerada un acontecimiento central en el derrumbe de la sociedad medioeval y la emergencia del mundo moderno ${ }^{13}$. Además, las epidemias de viruela e influenza han sido consideradas un elemento esencial para explicar como un puñado de soldados europeos lograron vencer la resistencia indígena durante la conquista del continente americano $^{6}$.

Por supuesto, varias de estas interpretaciones han generado importantes polémicas, y si bien hoy en día existe cierta tendencia a ser cautos frente al papel que pueda jugar un solo factor en los grandes cambios históricos ${ }^{6,12}$, hay un acuerdo básico en considerar la gran 
importancia que han tenido las epidemias en la historia de la humanidad ${ }^{5,7}$. Para el caso de la gripe de 1918, resulta de interés señalar que algunos investigadores han subrayado su importancia como factor que aceleró el final de la Primer Guerra Mundial y la firma de los acuerdos de paz en Versalles, mientras que otros han resaltado su significativo papel tanto en la crítica a los Estados como en la reconfiguración política en algunos territorios. Por ejemplo, Victoria Blacik nos muestra como la epidemia de gripe proporcionó un foro de discusión para expresar las insatisfacciones con el funcionamiento del Estado moderno lo cual, a su vez, contribuyó a la desestabilización del sistema político de la Restauración, en la España de comienzos del siglo $\mathrm{XX}^{14}$.

Por su parte, Christiane Cruz de Souza nos ha mostrado como la epidemia de gripe se insertó en una crítica situación social y política en la ciudad de Salvador de Bahía (Brasil) y como ella misma fue utilizada por los diversos grupos que lucharon por el control político del Estado. La situación generada por la epidemia se aprovechó para denunciar la crisis financiera del Estado, el nepotismo presente en la administración pública y las debilidades del servicio público de salud ${ }^{15}$. Y algo análogo pasó en el caso colombiano, puesto que la epidemia sirvió como pretexto para dirigir fuertes críticas al gobierno nacional el cual, por demás, mostró una debilidad extraordinaria, tanto así que se ha llegado a afirmar que la Junta Central de Higiene fue una víctima más de la epidemia ${ }^{16}$. También se ha podido establecer que la conciencia social generada a partir de la epidemia en la ciudad de Bogotá, permitió iniciar una serie de transformaciones importantes que reconfiguraron el espacio urbano capitalino con la construcción de los barrios obreros ${ }^{17}$.

Como se puede apreciar, las consecuencias de las pandemias pueden llegar a ser trascendentales y de un gran alcance político. Pero también es importante resaltar su papel como fuente de desorden social, miedo colectivo y cambios más profundos en la cultura. La descripción que hace Tucídides, de la epidemia de Atenas, no deja duda al respecto, como tampoco lo hacen los elocuentes relatos de Giovanni Boccaccio y de Robert Gottfried, acerca de lo ocurrido en la epidemia de la peste negra, en la Edad Media. Como lo menciona Tucídides.

"También en otros aspectos la epidemia acarreó a la ciudad una mayor inmoralidad. La gente se atrevía más fácilmente a acciones con las que antes se complacía ocultamente, puesto que veían el rápido giro de los cambios de fortuna de quienes eran ricos y morian súbitamente, y de quienes antes no poseían nada y de repente se hacían con los bienes de aquéllos. Asi aspiraban al provecho pronto y placentero, pensando que sus vidas y sus riquezas eran igualmente efimeras. $Y$ nadie estaba dispuesto a sufrir penalidades por un fin considerado noble, puesto que no tenía la seguridad de no perecer antes de alcanzarlo"18.

Este fragmento pone de presente el relajamiento de los códigos morales de la población atenienses agobiada por la epidemia. Fenómeno también descrito por Boccaccio, en su famosa obra El Decamerón, donde diez jóvenes que huyen de la Muerte Negra se distraen y divierten contando cuentos irreverentes. Allí se lee,

"Tales cosas y otras semejantes o peores engendraron en quienes quedaban con vida diversos temores y figuraciones; y casi todo desembocaba en un fin harto cruel: esquivar a los enfermos y sus cosas y huir de ellos; al obrar así, creía cada cual asegurar la propia salud. Había quienes pensaban que la sobriedad y la moderación les harían resistir la desgracia y, formando sus grupos, vivian separados de los demás [...] Otros, inclinados a la opinión contraria, afirmaban que la mejor medicina para tanto mal era beber mucho, disfrutar, cantar $y$ divertirse, satisfacer lo mejor posible todos los caprichos y reírse y burlarse de cuanto ocurría; y tal como lo decían lo ponían en obra como podían, yendo dia y noche de taberna en taberna, bebiendo sin tasa ni medida, y lo mismo y más hacian en las casas ajenas, con tal de que en ellas hubiera cosas que les agradaran"19.

Entre los cambios profundos mencionados, pueden señalarse la transformación del sentido del tiempo y el hecho de que la vida adquirió tonalidades más violentas y emotivas. Al decir de Gottfried,

"Gran parte de la crueldad y la violencia así como de la piedad y la alegría de finales del siglo XIV y del XV sólo pueden comprenderse teniendo en cuenta la nueva omnipresencia de la peste y la posibilidad de la muerte súbita y dolorosa. En la Alta Edad Media, época de expansión y madurez, la literatura y las artes expresaban un boyante optimismo. Después de la Muerte Negra, esto fue reemplazado por un casi omnipresente pesimismo" 20 . 
En segundo lugar, merece resaltarse que un aspecto dramático de la respuesta de las poblaciones a las epidemias es el deseo de establecer responsabilidades y buscar culpables. Esto puede generar intensos sentimientos xenofóbicos. Eso ocurrió, por ejemplo, en las epidemias ocurridas en el ocaso del Imperio Romano, cuando se culpó a los cristianos, mientras que en la peste negra se culpó a los judíos. Cabe recordar, por demás, que a la sífilis se le llamo mal francés en Inglaterra y Alemania, mal napolitano en España, la enfermedad española en Francia, mal chino en Japón y enfermedad polaca en Rusia ${ }^{11}$. Otro tanto pasó con la gripe de 1918, la cual se apodó española en Europa y Estados Unidos, mientras los alemanes la llamaron la fiebre de Flandes.

En general, cada vez que aparece una epidemia en algún lugar, aparece la tendencia a buscar un chivo expiatorio. Este fenómeno lo estudiaron con cierto detalle Cristina Oehmichen y María Dolores Paris en el caso de la epidemia de influenza en México, conocida como la epidemia de gripe porcina. En su trabajo se muestra como la epidemia puso al descubierto los procesos simbólicos que intervienen en la construcción de un chivo expiatorio, lo cual conlleva toda una secuela expresada en fenómenos de discriminación discreta, formas de evitamiento y segregación e, incluso, actos abiertos de racismo y xenofobia. Las autoras llegan a plantear la existencia de un racismo sanitario ${ }^{21}$.

En tercer lugar, y muy vinculado a lo anterior, cabe señalar que las epidemias producen mucho temor colectivo y, por ello, favorecen la estigmatización. Basten dos ejemplos para ilustrar el asunto. En los comienzos de la epidemia de VIH-SIDA, los enfermos cargaban con una pesada carga al tener que soportar no sólo las consecuencias físicas de la enfermedad sino los atributos morales que se les asignaban: promiscuidad, irresponsabilidad, suciedad y depravación. Y esto generó intensas dinámicas de discriminación, tal como fue analizado hace varios años por la reconocida intelectual estadounidense Susan Sontag 22 y, más recientemente, por la campaña mundial contra el VIHSida, en el año $2002^{23}$. Dinámicas de discriminación que también se hicieron presentes durante la epidemia de gripe porcina en el año 2009, tal como lo muestran Oehmichen y Paris, en el texto arriba mencionado ${ }^{21}$.

En cuarto lugar, cabe señalar que las intervenciones médicas y de salud pública a menudo no cumplen sus promesas. O se demoran mucho en cumplirlas, lo cual genera frustración y dudas frente al saber médicosalubrista. Tal como lo señala Jones, la vacunación contra la viruela tardó muchos años en alcanzar su éxito $^{3}$. Un poco más de dos siglos, desde los iniciales esfuerzos de variolización por parte del médico Giacomo Pilarini ${ }^{11}$, y casi 180 años desde la descripción del procedimiento por parte del médico Edward Jenner $^{3}$. Aquí, nuevamente, es de resaltar lo ocurrido con la gripe de 1918. Los esfuerzos terapéuticos fueron infructuosos, pese a que se ensayó con una gran cantidad de sustancias y fórmulas médicas ${ }^{24,25}$.

Por último, cabe retomar como un claro aprendizaje de la experiencia con las epidemias el que, pese a lo dramático que resultan y a lo catastrófico que pueden llegar a ser, la vida continua y la gente se sobrepone a ellas, de la mejor manera posible. Tanto así que con el correr del tiempo se llega esa fase de olvido, a la que hacían referencia Rosenberg, Cueto y Martínez. Y eso ha pasado desde la plaga que azotó Egipto en el año 1500 a.C. hasta las más recientes epidemias. Aunque claro, los recuerdos de algunas epidemias pueden mantenerse durante mucho tiempo, ya sean décadas o aun siglos. Todas estas lecciones son de gran interés, puesto que permiten, por un lado, comprender la complejidad del fenómeno epidémico y, por otro lado, prever algunas consecuencias que se deben tener en cuenta a la hora de organizar acciones para enfrentar una epidemia. Sin embargo, por su carácter general, puede que no conmuevan lo suficiente a quienes tengan un temperamento más pragmático. Por ello, vale la pena señalar algunas lecciones más específicas, que refuerzan los aprendizajes más generales.

\section{Lecciones más específicas del estudio de las pandemias}

Para muchos expertos sanitaristas, el pasado proporciona un prólogo necesario para cualquier discusión sobre enfermedades infecciosas emergentes, y más aún para las reemergentes, ya sea que esa discusión se refiera a los orígenes biológicos de una pandemia potencial o a sus repercusiones sociales. Y esto se evidencia no sólo en el hecho de la existencia de foros y demás eventos académicos donde se reúnen salubristas e historiadores médicos para el estudio de las epidemias del pasado, sino también en el hecho de que dicho estudio forma parte esencial del trabajo cotidiano de muchos expertos interesados en el enfrentamiento de las enfermedades infecciosas, de carácter epidémico.

Por ejemplo, al reflexionar sobre los principales brotes de enfermedades infecciosas emergentes y reemergentes durante el último cuarto del siglo XX y los comienzos del siglo XXI, David Heynman, funcionario de alto 
nivel de la Organización Mundial de la Salud y experto en la acción preventiva contra la poliomielitis, puso de manifiesto lo que estos episodios revelaban sobre las funciones y responsabilidades de los trabajadores de la salud en una pandemia, las consecuencias de las enfermedades infecciosas en el comercio mundial, el desafío de brindar acceso equitativo a los recursos asistenciales y el equilibrio de los derechos individuales frente al bienestar público. Y en su análisis mostró cómo el creciente reconocimiento de la amenaza que representan las enfermedades infecciosas emergentes condujo a una mayor cooperación internacional en la notificación y respuesta a los brotes de enfermedades, como se ilustra durante el primer brote del síndrome respiratorio agudo severo, conocido por su sigla SARS, en los años 2002 y $2003^{26}$.

Por su parte, el médico e historiador de la medicina Howard Markel, en una reflexión sobre el papel de la investigación histórica en el desarrollo de las estrategias de mitigación de las pandemias, señala que,

"Dado que una epidemia representa un laboratorio social vivo, proporciona una ventana útil a través de la cual se puede ver la capacidad de recuperación y la eficiencia de las estructuras administrativas de una sociedad en particular, sus fortalezas y deficiencias políticas y sociales, y su compromiso con los rumores, las sospechas o la mala conducta. Después de todo, las epidemias no son ocasiones tranquilas; son experimentados $y$ respondidos en tiempo real por la comunidad afectada y luego descubiertos, anunciados y explicados por historiadores como yo. Como resultado, el registro histórico de estos eventos es especialmente rico y provocativo"27.

Resulta muy llamativo, por demás, como el análisis de la experiencia de la influenza estadounidense de 1918 le permite al autor afirmar que dicha pandemia constituye una de las bases de datos más grandes jamás reunidas en la era moderna, posterior a la teoría de los gérmenes, sobre el uso de intervenciones no farmacológicas para mitigar la influenza pandémica en centros urbanos. Esto, de por sí, puede tener un gran interés para quienes elaboran políticas, puesto que les da la oportunidad de observar cómo responde una sociedad ante una amenaza pandémica, cuando no existían vacunas ni antivirales. Y la historia sugiere que cuando las sociedades (y comunidades) se enfrentan a crisis de este tipo adoptan, de una forma u otra, lo que perciben como medidas efectivas de distanciamiento físico y otras formas de aislamiento ${ }^{27}$.

Por ahora, interesa resaltar tres lecciones de índole más específica que pueden extraerse de las experiencias del pasado. En primer lugar, las medidas de aislamiento físico y cuarentena (lo que ahora suele incluirse bajo la noción de medidas de intervención no farmacológicas) funcionan, como ha sido señalado en repetidas ocasiones. Por supuesto, la eficacia de esas medidas depende del alcance, rigurosidad y oportunidad de su implementación y del carácter de la epidemia y su uso prolongado produce mucha controversia dado el impacto social y económico que conllevan y dados los retos éticos y políticos que traen.

Desde que empezó a usarse la cuarentena como forma de control de las epidemias, en el siglo XIV, en Dubrivnick en la costa croata y en la colonia veneciana de Ragusa, la medida ha tenido logros significativos. Cabe recordar que en ese puerto veneciano, de gran importancia en la época, se construyó un centro de aislamiento llamado lazzaretto en una isla cercana, donde se enviaba a las tripulaciones de barcos infectados para permanecer allí hasta su muerte o recuperación. Luego se construyeron varios de estos centros de cuarentena en otros lugares alrededor del mundo. Si bien el contexto de su génesis está asociado a la peste negra medieval, por lo común la historia de la cuarentena también se vincula estrechamente al manejo de las epidemias de cólera y fiebre amarilla, en los siglos XVIII y XIX ${ }^{28}$.

Muy vinculado al uso específico de la cuarentena, también ha estado presente, como una medida de salud pública tradicional, el distanciamiento físico de las personas sanas así como el cierre de espacios de la vida social. Quienes estudian la epidemia de gripe de 1918 han mostrado el uso extendido de esas prácticas. En nuestro contexto local colombiano, por ejemplo, las medidas de cierre de iglesias, colegios y plazas de mercado, entre otros sitios, así como la prohibición de reuniones masivas fueron comunes y formaron parte de las estrategias higiénicas adoptadas en su momento, al mismo tiempo que se convirtieron en sucesos generadores de ansiedad y preocupación entre la población bogotana de comienzos del siglo $\mathrm{XX}^{29,30}$.

Y esto mismo pasó en muchos otros lugares, como lo muestra la extensa bibliografía que hay sobre el tema, aunque la intensidad de las medidas fue diferente dependiendo de las características de cada uno de los contextos locales ${ }^{31,32}$. Pero más allá de la descripción de las medidas tomadas, llama la atención un conjunto de trabajos que han aprovechado la experiencia histórica 
para valorar, con más detalle, la eficacia de las medidas. Eso lo hacen tanto Hatchett, et al. ${ }^{33}$ como Markel, et al. ${ }^{34}$, utilizando bases de datos construidas con la información de la epidemia en los Estados Unidos.

El trabajo del grupo de Hatchett analizó datos frente a lo ocurrido en 17 ciudades de los Estados Unidos y buscó probar la hipótesis que afirma que la implementación temprana de múltiples intervenciones no farmacológicas se asoció con una menor transmisión de la enfermedad. Usando los recursos del análisis estadístico, los autores compararon las medidas de salud pública de las distintas ciudades en contraste con los datos de mortalidad en cada una de ellas, encontrando algunas diferencias importantes. La más llamativa fue el fuerte contraste entre lo ocurrido en las ciudades de Filadelfia y San Luis. Mientras que en la primera las medidas sanitarias fueron tardías, en la segunda fueron muy rápidas y esto tuvo claras y dramáticas consecuencias en la mortalidad por la epidemia. La figura que presentan, mostrando el comportamiento de las tasas de mortalidad en las dos ciudades, es muy elocuente. Al final, los autores concluyen que la implementación temprana de ciertas intervenciones sanitarias se asoció con tasas máximas de mortalidad más bajas lo cual apoya la hipótesis de que la implementación rápida de múltiples medidas de intervención no farmacológica reduce significativamente la transmisión de la influenza, aunque se estimó que la propagación viral se renueva al relajar tales medidas ${ }^{33}$.

Por su parte, el trabajo del equipo de Markel analizó la implementación de medidas no farmacológicas en 43 ciudades de los Estados Unidos con el fin de determinar si la variación de la mortalidad, de una ciudad a otra, se asociaba con el momento, la duración y la combinación de esas intervenciones. Recurriendo, igualmente, a los recursos del análisis estadístico, los autores concluyen que, efectivamente, existe una fuerte asociación entre la aplicación temprana, sostenida y en capas de dichas intervenciones y la mitigación de las consecuencias de la pandemia de influenza de 1918-1919, en los Estados Unidos.

Para efectos del análisis, las intervenciones se agruparon en tres categorías principales y una subsidiaria: cierre de escuelas, prohibiciones de reuniones públicas, aislamiento y cuarentena y medidas adicionales (como alteración de los horarios de trabajo, regulaciones de negocios, restricciones de transporte, comunicaciones de riesgo público y uso de mascarillas). Aunque hubo ciudades que usaron todos los tipos de medida, la combinación más común fue el cierre de escuelas y la prohibición de reuniones públicas. Los autores también resaltan lo ocurrido en Filadelfia, así como lo hicieron Hatchett, et al. pero el contraste lo hacen con la ciudad de Nueva York, ciudad que respondió ante la epidemia de manera rápida, sin esperar a que se acumulara un exceso de muertes ${ }^{34}$. Tal como lo estudió con detenimiento Francesco Aimone, Nueva York contó con una infraestructura sólida, la cual se había forjado en el enfrentamiento de enfermedades previas como la tuberculosis ${ }^{35}$.

Estos trabajos corroboran que las medidas de aislamiento y el cierre de espacios públicos y negocios funcionan aunque, por supuesto, tienen fuertes consecuencias sociales. Entre ellas cabe señalar la obstrucción de las dinámicas económicas y también el hecho de que a menudo favorecen el atropello de los derechos individuales en nombre del bien público. El uso del aislamiento para separar a las personas sospechosas de estar infectadas puede violar la libertad de personas sanas, lo cual suele ocurrir con mayor frecuencia en clases bajas y en grupos marginados. Estas medidas, como se mencionó más arriba, también han servido para generar estigma y discriminación para grupos específicos de la sociedad. Por ello, la discusión ética y política ha sido tan intensa frente al asunto.

En segundo lugar, cabe señalar que las epidemias alteran la sociedad en su conjunto pero tienden a profundizar las brechas sociales $\mathrm{y}$, por tanto, a ampliar la desigualdad social. El reconocimiento de la afectación diferencial viene de tiempo atrás pero, por supuesto, se hace más patente en las epidemias más recientes. Tal como ocurrió en la gripe de 1918, en Bogotá, la infección se expandió ampliamente por la población pero la mortalidad se concentró en la población pobre, en la llamada clase trabajadora. La epidemia dejó en claro las relaciones sociales existentes y produjo más desigualdad. Y no sólo se ensañó con la población en condiciones de miseria sino que produjo consecuencias como la elevación de los precios de muchos productos (entre los que se encontraban ataúdes, medicamentos, leche y algunas frutas que se usaban como remedios) lo que encareció la vida y afectó diferencialmente a los grupos sociales. Algunos de los nombres de los difuntos de clase pobre quedaron grabados en letra de imprenta, en la prensa local, pero sin las notas laudatorias que acompañaban el nombre de los difuntos de la clase pudiente ${ }^{36}$.

Este diferencial social frente a la muerte, que es extensible con cautela al ámbito de la morbilidad, ha sido expuesto por diversos autores y en relación 
con diferentes enfermedades. El reconocido médico antropólogo Paul Farmer así lo señala al analizar lo ocurrido con las llamadas enfermedades infecciosas emergentes, en los años 90 del siglo $\mathrm{XX}^{37}$, y también lo señala Marcos Cueto al estudiar las epidemias de cólera y dengue en el Perú, de finales del siglo $\mathrm{XX}^{38}$. Lo cual refuerza la idea, tan conocida en el campo de la salud pública, del estrecho vínculo entre pobreza, enfermedad y desigualdad sanitaria ${ }^{39}$. Esto conlleva una enseñanza secundaria que es esencial tener presente: la acción sanitaria frente a las epidemias debe incluir el criterio de equidad en salud.

En tercer lugar, y por último, cabe decir que el estudio de las epidemias del pasado nos ha enseñado que ellas son fenómenos complejos que vinculan de manera íntima la dimensión biológica con la dimensión social. Y esto conlleva la necesidad de abordajes socioambientales cada vez más sensibles a la propia complejidad. Cabe recordar el estudio realizado por Gottfried sobre la peste negra y cómo en él se muestra a la epidemia como parte de toda una crisis ambiental propia del final del período medieval ${ }^{20}$ así como el desgarrador estudio de Charles Briggs y Clara Mantini sobre la epidemia de cólera en Venezuela, entre 1992 y 1993, donde la acción frente a la epidemia conlleva todo un ejercicio de discriminación ${ }^{40}$. Pero tal vez sean los estudios sobre la gripe los que resultan más esclarecedores para mostrar esa interrelación.

Por supuesto, el estudio de la gripe de 1918 sigue siendo fundamental, y el análisis historiográfico de la producción académica muestra con elocuencia las múltiples dimensiones y repercusiones que tuvo la pandemia ${ }^{41}$. Y hoy en día se reconoce, con cierta amplitud, que la pandemia de 1918 fue el resultado de un proceso de configuración histórico-territorial complejo, en el cual los procesos biológicos y los procesos sociales se interrelacionaron íntimamente ${ }^{42}$. Como fenómeno que afectó profundamente la vida humana, la pandemia de 1918 insertó los vínculos entre agentes biológicos en las dinámicas sociales que configuran el mundo de los humanos.

Y esto también queda evidente en algunos trabajos que han empezado a estudiar, con detalle, otras pandemias de gripe. Baste mencionar, por lo pronto, que el reputado biólogo evolutivo Rob Wallace ha estudiado con cierta profundidad las epidemias de gripe aviar y gripe porcina y ha puesto en evidencia las relaciones existentes entre el agronegocio, el sistema capitalista y la propagación de enfermedades infecciosas. En últimas, su análisis de las condiciones en que viven los animales antes de ser sacrificados permite entender el por qué las granjas industriales favorecen el desarrollo de virus más patógenos y eficaces en su modo de transmisión. Dado que la inmunidad natural de los animales se afecta poderosamente, en esas condiciones, y el intercambio viral entre especies se incrementa, el resultado común es la exportación de enfermedades desde estas granjas a todo el mundo, a través de las redes comerciales conectadas globalmente ${ }^{43}$.

La sugerente aproximación que hace Wallace, la cual involucra aspectos virológicos, ecológicos, sociológicos y de economía política, proporciona una fructífera visión de conjunto que permite no sólo complejizar el análisis sino imaginar formas alternas de enfrentar la problemática de las pandemias. En palabras del propio Wallace,

"De hecho, la influenza puede ser definida por
su estructura molecular, por la genética, por la
virología, por la patogénesis, por el huésped
biológico, el curso clínico, el tratamiento, las
formas de transmisión, y la filogenética. Ese
trabajo es, desde ya, esencial. Pero al limitar
la investigación a esos tópicos se pierden
los mecanismos críticos que están operando
en otros amplios niveles de organización
socio ecológica. Estos mecanismos incluyen
cómo el ganado es adquirido y organizado
a través del tiempo y del espacio. En otras
palabras, necesitamos ir hacia las decisiones
especificas que toman gobiernos y compañas
particulares que promueven la emergencia
de gripes virulentas. Pensar solamente de
forma virológica hace desaparecer esas
explicaciones, muy en favor de la industria
porcina"43.

Llamado fundamental que permite reforzar los estudios de historiadores y científicos sociales, quienes desde su propia perspectiva abogan por miradas multidimensionales y enfoques integradores acordes con la complejidad del fenómeno pandémico. Por todo esto, se puede considerar que la corroboración de la efectividad de ciertas acciones sanitarias, la exaltación de la necesidad de luchar en contra de la desigualdad al enfrentar las epidemias y la emergencia de renovadores y más integradores enfoques analíticos son algunas de las enseñanzas, más específicas, que nos aporta el estudio de las epidemias del pasado. 
Bogotá, agosto de 2020

\section{Referencias}

1. Cueto M. La covid-19 y las epidemias del neoliberalismo. El País (Madrid). 2020. https:// elpais.com/ciencia/2020-03-27/la-covid-19-y-lasepidemias-del-neoliberalismo.html

2. Martínez AF. De la negación al olvido, historia de pandemias. Rev Fac Nal Salud Pública 38(2); 2020: 1-2. doi: https://doi.org/10.17533/udea.rfnsp. e341898

3. Jones DS. History in a crisis. Lessons for COVID 19. N Engl J Med. 2020; 382(18); 1681-1683. doi: 10.1056/NEJMp2004361

4. Eslava JC. Las causas socioambientales de la pandemia COVID 19. Rev Fac Nal Salud Pública. 2020; 38(3): 4-5. doi: https://doi.org/10.17533/ udea.rfnsp.e342049

5. McNeill W. Plagas y Pueblos. Siglo XXI España Editores, Madrid, 1994.

6. Cook ND. La conquista biológica. Las enfermedades en el Nuevo Mundo. Siglo XXI España Editores, Madrid, 2005.

7. Oldstone M. Virus, pestes e historia. Fondo de Cultura Económica, México, 2002.

8. Breilh J. SARS-CoV2: rompiendo el cerco de la ciencia del poder. Escenario de asedio de la vida, los pueblos y la ciencia. En: Posnormales. Editorial ASPO, Provincia de Buenos Aires, 2020: 31-89

9. Franco S. El paludismo en América Latina. Editorial Universidad Guadalaja, 1990.

10. Khams R. The History of Pandemics Teaches Us Only That We Can't Be Taught. Wired. 2020; https:// www.wired.com/story/the-history-of-pandemicsteaches-us-only-that-we-cant-be-taught/

11. Cartwright F, Biddiss M. Grandes pestes de la historia. Editorial El Ateneo, Buenos Aires, 2005.

12. Mordechai L, Eisenberg M. Rejecting catastrophe: the case of the justinianic plague. Past \& Present. 2019; 244(1): 3-50. doi: https://doi.org/10.1093/ pastj/gtz009

13. Porter D. Pestilence and public order in medieval Europe. In: Health, Civilization and the State. A history of public health from ancient to modern times. Routledge. London \& New York, 1999: 24-45

14. Blacik V. De la desinfección al saneamiento: críticas al Estado español durante la epidemia de gripe de 1918. Ayer. 2009; 75(3): 247-273.
15. Souza CM. “A gripe espanhola em Salvador, 1918: cidade de becos e cortiços". História, Ciências, Saúde, Manguinhos. 2005; 12(1): 71-99. doi: https:// doi.org/10.1590/S0104-59702005000100005

16. Martínez AF, Meléndez BF, Manrique EJ. La Junta Central de Higiene de Colombia, otra de las víctimas de la pandemia de gripa de 1918-1919. Astrolabio. 2014; 13: 5-37.

17. Cifuentes JA. Barrios obreros en Bogotá. San Cristóbal y la vivienda obrera, 1910-1940 (Tesis de Grado). Maestría en Historia. Facultad de Ciencias Humanas. Universidad Nacional de Colombia, Bogotá, 2018

18. Tucídides. Historia de la Guerra del Peloponeso Libro I y II. Biblioteca Clásica Gredos, Epulibre, Editor digital Titivillus, 2019.

19. Boccaccio G. El Decamerón. Alianza Editorial, Madrid, 2014

20. Gottfried R. La muerte negra. Desastres naturales y humanos en la Europa medieval. Fondo de Cultura Económica, México, 1989

21. Oehmichen C, Paris MD. El rumor y el racismo sanitario durante la epidemia de influenza A/H1N1. Cult Rep Sociales. 2010; 5(9): 145-173.

22. Sontag S. La enfermedad y sus metáforas y El Sida y sus metáforas. Taurus, Madrid, 1996.

23. ONUSIDA. Marco conceptual y base para la acción: Estigma y discriminación relacionados con el VIH/ SIDA. Ginebra, 2002.

24. Porras MI. Sueros y vacunas en la lucha contra la pandemia de gripe de 1918-1919 en España. Asclepio. 2008; 60(2): 261-288.

25. Eslava JC, García M, Guevara AP. Las ideas médicas sobre la epidemia de gripa de 1918 en Bogotá. Rev Fac Medicina UN. 2010; 58(1): 84-97.

26. Heyman D. Past as prologue? In: Ethical and Legal Considerations in Mitigating Pandemic Disease: Workshop Summary. Washington, DC: The National Academies Institute of Medicine, 2007: 33-44.

27. Markel H. Contemplating pandemics: the role of historical inquiry in developing pandemic-mitigation strategies for the twenty-first century. In: Ethical and Legal Considerations in Mitigating Pandemic Disease: Workshop Summary. Washington, DC: The National Academies Institute of Medicine, 2007: 44-60.

28. Tognotti E. "Lessons from the History of Quarantine, from Plague to Influenza A". Em Inf Diseases. 2013; 19(2): 254-259.

29. Martínez AF, Manrique FG, Meléndez BF. La pandemia de gripa de 1918 en Bogotá. Dynamis. 2007; 27: 287-307. 
30. Eslava JC, García M, Bernal S. Dudas y desasosiego ante la epidemia de Gripa en Bogotá, Colombia, en 1918. Americania. Rev Estudios Latinoamericanos. 2017; 6: 110-135. https://www.upo.es/revistas/ index.php/americania/article/view/2327/2327

31. Botey AM. La tardía epidemia de influenza o gripe 'española' y sus desenlaces en Costa Rica (19181920). Americania. Rev Est Latinoamericanos. 2017; 6: 77-109. https://www.upo.es/revistas/index. php/americania/article/view/2356

32. Bortz JE 1918: La grippe en Buenos Aires. La sociedad porteña en crisis. Americania. Rev Est Latinoamericanos. 2017; 6; 2017: 230-261. https:// www.upo.es/revistas/index.php/americania/article/ view $/ 2364$

33. Hatchett R, Mecher C, Lipsitch M. Public health interventions and epidemic intensity during the 1918 influenza pandemic. PNAS. 2007; 104(18): 75827587. doi: https://doi.org/10.1073/pnas.0610941104

34. MarkelH,Lipman H, Navarro JA, SloanA, Michalsen JR, Minna Stern A, et al. Nonpharmaceutical Interventions Implemented by US Cities During the 1918-1919 Influenza Pandemic. JAMA. 2007; 208(6): 644-654. doi: 10.1001/jama.298.6.644

35. Aimone F. The 1918 Influenza epidemic in New York city: A review of the public health response. Public Health Rep: . 2010; 125(suppl 3): 71-79. doi: $10.1177 / 00333549101250$ S310

36. Miranda A. Treinta días persiguiendo la muerte: miseria, dolor y obras de caridad en Bogotá de 1918, desolada por la epidemia de gripa. Bol Cul Biblio. 2008; 45(78): 41-61.

37. Farmer P. Desigualdades sociales y enfermedades infecciosas emergentes. Pap Poblac. 2000; 23: 181-201.

38. Cueto M. "Cólera y dengue en Lima al final del siglo XX y comienzos del XXI: salud y la cultura de la sobrevivencia”. En: Historia social y urbana. Espacios y flujos. Kingman E (editor). Clacso, Quito. 2009; 253-272.

39. Wagstaff A. Pobreza y desigualdades en el sector de la salud. Rev Paname Salud Pública. 2002; 11(5-6); 2002: 316-326. doi: 10.1590/S102049892002000500007

40. Briggs C, Mantini C. Las historias en los tiempos del cólera. Nueva Sociedad/GTZ, Venezuela, 2004.

41. Phillips H. The Recent Wave of 'Spanish' Flu Historiography. Soc Hist Medicine. 2014; 27(4): 789-808. https://doi.org/10.1093/shm/hku066
42. Henao L. Hernández M. "La pandemia de gripe de 1918: un caso de subsunción de lo biológico en lo social". Americania. Rev Est Latinoamericanos. 2017; 6: 8-52. https://www.upo.es/revistas/index. php/americania/article/view/2742

43. Wallace R. Big farms make big flu. Dispatches on infectious disease, agribusiness, and the nature of science. Monthly Review Press, New York, 2016. 